\title{
Correction to: Methods in the design and implementation of the Randomized Evaluation of Sedation Titration for Respiratory Failure (RESTORE) clinical trial
}

Martha A. Q. Curley ${ }^{1,2,3}$, Rainer G. Gedeit ${ }^{4,5^{*}}$, Brenda L. Dodson ${ }^{6}$, June K. Amling ${ }^{7}$, Deborah J. Soetenga ${ }^{8}$, Christiane O. Corriveau' ${ }^{9}$, Lisa A. Asaro ${ }^{10}$, David Wypij ${ }^{10,11,12}$ and For the RESTORE Investigative Team

Correction to: Trials (2018) 19:687

https://doi.org/10.1186/s13063-018-3075-8

Following publication of the original article [1], the authors notified us of a typing error in spelling Dr. Asario's name. The original publication has been corrected.

- Originally published name:

Lisa A. Asario

- Corrected name:

Lisa A. Asaro

\begin{abstract}
Author details
'School of Nursing, University of Pennsylvania, Philadelphia, PA, USA. ${ }^{2}$ Perelman School of Medicine at the University of Pennsylvania, Philadelphia, PA, USA. ${ }^{3}$ Research Institute, Children's Hospital of Philadelphia, Philadelphia, PA, USA. ${ }^{4}$ Department of Pediatrics, Medical College of Wisconsin, Milwaukee, WI, USA. ${ }^{5}$ Critical Care Section, Children's Hospital of Wisconsin, 9000 W. Wisconsin Avenue, MS \#681, Milwaukee, WI 53226, USA. ${ }^{6}$ Information Services Department, Boston Children's Hospital, Boston, MA, USA. ${ }^{7}$ Department of Plastic Surgery, Children's National Health System, Washington, DC, USA. ${ }^{8}$ Pediatric Intensive Care Unit, American Family Children's Hospital, Madison, WI, USA. ${ }^{9}$ Department of Critical Care Medicine, Children's National Medical Center, Washington, DC, USA. ${ }^{10}$ Department of Cardiology, Boston Children's Hospital, Boston, MA, USA. ${ }^{11}$ Department of Biostatistics, Harvard School of Public Health, Boston, MA, USA. ${ }^{12}$ Department of Pediatrics, Harvard Medical School, Boston, MA, USA.
\end{abstract}

Received: 19 December 2018 Accepted: 19 December 2018 Published online: 07 January 2019

\section{Reference}

1. Curley MAQ, et al. Methods in the design and implementation of the Randomized Evaluation of Sedation Titration for Respiratory Failure (RESTORE) clinical trial. Trials. 2018;19:687. https://doi.org/10.1186/s13063018-3075-8.

\footnotetext{
* Correspondence: rgedeit@mcw.edu

${ }^{4}$ Department of Pediatrics, Medical College of Wisconsin, Milwaukee, WI, USA ${ }^{5}$ Critical Care Section, Children's Hospital of Wisconsin, 9000 W. Wisconsin Avenue, MS \#681, Milwaukee, WI 53226, USA

Full list of author information is available at the end of the article
}

(c) The Author(s). 2019 Open Access This article is distributed under the terms of the Creative Commons Attribution 4.0 International License (http://creativecommons.org/licenses/by/4.0/), which permits unrestricted use, distribution, and reproduction in any medium, provided you give appropriate credit to the original author(s) and the source, provide a link to the Creative Commons license, and indicate if changes were made. The Creative Commons Public Domain Dedication waiver (http://creativecommons.org/publicdomain/zero/1.0/) applies to the data made available in this article, unless otherwise stated. 